\title{
Erratum to: Does the Recent Growth of Aquaculture Create Antibiotic Resistance Threats Different from those Associated with Land Animal Production in Agriculture?
}

\author{
Hansa Y. Done, ${ }^{1,2}$ Arjun K. Venkatesan, ${ }^{1}$ and Rolf U. Halden ${ }^{1,2,3,4}$
}

\section{Erratum to: AAPS J}

DOI 10.1208/s12248-015-9722-z

In the third paragraph under the headers "Agriculture vs. Aquaculture" and secondarily "Animal Farming and Antibiotic Usage," the authors inadvertently used the wrong unit of measurement regarding antibiotic usage in salmon. The correct sentence should read:

For example, in 2003, salmon aquaculture in Chile used about $0.5 \mathrm{~kg}$ of antibiotic for each metric ton of salmon produced, whereas the amount in Norway was $0.002 \mathrm{~kg}$ (26).

The online version of the original article can be found at http:// dx.doi.org/10.1208/s12248-015-9722-z.

\footnotetext{
${ }^{1}$ Center for Environmental Security, The Biodesign Institute, Arizona State University, 781 E. Terrace Mall, Tempe, Arizona 85287, USA.

${ }^{2}$ Biological Design Graduate Program, School of Biological and Health Systems Engineering, Arizona State University, Tempe, Arizona 85287, USA.

${ }^{3}$ Department of Environmental Health, Bloomberg School of Public Health, Johns Hopkins University, Baltimore, Maryland, USA.

${ }^{4}$ To whom correspondence should be addressed. (e-mail: halden@asu.edu)
} 